\title{
The Role of Language-Game in Sociocultural Adaptation: Russian Students in France
}

\author{
Svetlana Sablina ${ }^{1} \&$ Olga Kopiatina ${ }^{1,2}$ \\ ${ }^{1}$ Department of Sociology, Novosibirsk State University, Novosibirsk, Russia \\ ${ }^{2}$ Department of Education, University of Maryland, Baltimore County, Baltimore, USA \\ Correspondence: Olga Kopiatina, 1140 Linden avenue, Halethorpe, MD 21227, USA. Tel: 1-443-636-7495. \\ E-mail: olgako1@umbc.edu
}

\author{
Received: February 11, 2013 Accepted: February 21, 2013 Online Published: March 4, 2013 \\ doi:10.5539/ies.v6n4p10 \\ URL: http://dx.doi.org/10.5539/ies.v6n4p10
}

\begin{abstract}
Higher educational institutions throughout the world are involved in communication with each other, exchanging instructional ideas and practices, as well as exchanging students through a number of international mobility programs. This paper examines sociocultural adaptation of international students with special attention to the dimensions of adaptation viewed from the perspective of language-game. For this purpose, 34 Russian students who study in French universities and higher schools ("grandes écoles") as exchange students were interviewed in Paris (France) and Novosibirsk (Russia). The research shows that language-game is used in different dimensions of adaptation related to educational system, sociocultural context, mentality, and sociopolitical life. In order to overcome problems in adaptation and establish successful interaction, students use language-game to adjust to the unfamiliar social, cultural, and educational contexts.
\end{abstract}

Keywords: sociocultural adaptation, language-game, student exchange programs, internationalization of education

\section{Introduction}

\subsection{The Influence of Globalization on Higher Education}

Modern higher education cannot be viewed out of the context of globalization. The process of globalization has influenced the expansion of various learning practices outside the borders of one country or one educational system. International academic mobility has become an important characteristic of higher education. According to the UNESCO Institute of Statistics, the number of globally mobile students increased to 3.4 million in 2009 , up from 2.1 million in 2002 (Note 1).

Many countries still preserve their unique national systems of human development that are influenced by cultural patterns and institutional mechanisms of translating social values and norms from one generation to another. However, it becomes more and more obvious that there are certain long-term economic, academic, and social benefits that countries may receive through the internationalization of education, i.e. through the influx of international students. In the competitive world education market (Tran, 2008), for example, universities and higher schools that are on the top places in the Academic Ranking of World Universities, or Shanghai Ranking, are very likely to be attractive to a larger number of domestic and international students. Therefore, for most schools, internationalization becomes inevitable.

International student exchange programs stimulate interaction between the partners with different linguistic, social, and communicative worldviews, i.e. norms, values, beliefs, and attitudes (Sablina, 2004; Onorati, 2010). Students who go abroad to study face the need to revise the methods to perceive and estimate the world introduced by their national education system, and as a result, revise the behavioral models that were accepted and justified in a sociocultural environment that used to be familiar to them. This revision is a very important process that forms the ability to adjust to unusual behavioral models, comply with a new system of rules, and integrate into it, developing tolerance and respect to its values (Sisko \& Reinhard, 2007). In the case when norms and values are changeable, established by contingent conventions, collaborative actions of all partners determine the effectiveness of interaction. The representatives of different cultures, being in a dialogue, can select the 
appropriate behavioral patterns and ethical standards that are either presupposed or articulated by the situation (Sablina, \& Struminskaya, 2011).

\subsection{Adaptation of International Students in France under the Tendencies of Integration and Diversification}

France is known as a country with a large amount of international students (Tremblay, 2010). Universities and higher schools offer various educational opportunities that, in terms of the domestic market only, exceed the actual demand. Therefore, French higher educational institutions not only allow, but even desire the high influx of international students, including the Russian youth.

There is no doubt that France has rich culture, history, and educational traditions reflected in the idea of collective identity (Linklater, 2011). The world community has been continuously interested in the specific character of French "cultural policy," which is exclusively a French "invention" (Kosenko, 2008). At the turn of the 20th century, the country became a world cultural center due to the defense and preservation of its national identity and authenticity, including the support of the French language.

The unique identity of France has become apparent in its inordinate politicization of the society reflected not only in the political rhetoric, but also in everyday life of the French citizens. Even an unexperienced observer can notice political debates that shape the foreground of the life scene, with all the rest being the backstage activities. Taking into account the specific educational, cultural, and political situation, we can understand why the sociocultural adaptation that international students experience is such a complex process.

Under conditions of globalization, the two opposite tendencies of educational, economical, political, and cultural systems development could be observed: integration and diversification. The history has shown that there is no preference for either of them as they balance and complement each other. However, for a short period of time, one of them can become more obvious than the other. Currently, integration is viewed as a much more ideologically attractive construct, which can be perceived as an indicator of successful activities of political subjects. The desirable integration is very likely to be the "system integration," which is defined by Anthony Giddens as "reciprocity of actors in contexts of co-presence" (1984, p. 28). Thereby, the range of problems associated with integration and solidarity of the society, being largely represented in the public rhetoric, tends to penetrate into the minds of people.

\section{Background of the Study}

\subsection{Language-Game in the New Philosophy of Communication}

We suggest to examine the process of sociocultural adaptation from the perspective of "language-game" introduced by Ludwig Wittgenstein (1958) and supported by Jean-Francois Lyotard (1986), Umberto Eco (1989, 2004), and Richard Rorty (1989). The attractiveness of this concept is predetermined by a new philosophy of communication that focuses on the variety of interpretations of social reality, rather than searching for one explanation that would be true for all cases. Janet Horne writes that Rorty "challenges us to consider new ways of thinking" (1989, p. 256) about communication and intercultural communication in particular, as a constantly changeable language-game where each new dialogue creates new rules for the game (Lyotard, 1986). The successors of the linguistic approach see the world as relative, full of contingencies, and inseparable from the language which becomes another means for the people to adjust to the environment, acting to meet their interests (Ryklin, 1996).

Both Lyotard and Rorty recognize the fact that language is an instrument of communication. However, they interpret the goals of a language-game in different ways. Lyotard emphasizes the critical anti-consensus perception of the world, saying that "The first principle... to speak is to fight... not necessarily to win... [but for pleasure]... (but there is pleasure in winning even if only over convention)" (1986, p. 10), while Rorty (1989) focuses on solidarity, i.e. the ability of the participants to agree about the rules and reach a consensus through a language-game.

Redescription, along with language-game and solidarity, has an important place in Rorty's (1989) theory. Redescriptions can be defined as new interpretations of objective reality that are created as responses to the changes in this objective reality. However, it is possible that a person chooses only one interpretation without making efforts to redescribe and, this way, understand and accept changes in the environment and his or her life.

Most humans adhere to a set of words which they employ to justify their actions, beliefs, and their lives. With the help of these words people tell stories of their lives, planning the event of their future or looking back to the past. Rorty (1989) calls this set of words "final vocabulary" which may be a product of life experiences, as well as common sense that provokes "commitment to words," an opposition to a language-game. He claims that it is impossible to use the same set of words, or the same final vocabulary, in different contexts of communication. 
Finding transitions and similarities between the vocabularies can guarantee not only successful communication, but also peaceful coexistence of communities.

Rorty (1989) sees the tragedy of the modern world in the fact that the majority of the people still tend to show "commitment to words" and "common sense" rather than create and utilize alternative descriptions of the reality. They want to be accepted in their own words and treated seriously as they speak. In contrast to the people who rely on common sense, Rorty introduced the so-called "ironic" type of personality which accepts contingency, changeability and relativity of the world, along with the variety of vocabularies and redescriptions that can be used in order to reach solidarity with others. The ironic personality understands that anything could be redescribed and, this way, understood and accepted into his or her expanded vocabulary. The main characteristics of such individuals include irony towards themselves, the use of language-game, and the flexibility to change according to the situation, embracing ambiguity, constantly revising values and norms, and questioning the existence of absolute truth.

\subsection{Research Questions and Objectives}

The ideas of Rorty, Eco, and Lyotard prompted us to investigate whether the use of language-game is a means of sociocultural adaptation, in particular, the adaptation of Russian students in France. Adapting to a different cultural environment, people with common sense are more likely to experience "culture shock." They face with the contradiction of the "real" to the "expected" and the discrepancy between certain actions and the words, on the one hand, and the norms of a different culture, on the other hand (Sumer, 2009). We suggest that Russian students in France, along with other international students in other countries, become the generators of new descriptions, using the language as a means of entering a different cultural and educational environment. In this case, language has to be understood in a broader meaning; it is not just French or Russian, but, generally speaking, it is language that is used as a tool of communication.

We hypothesized that international students, Russian students in France in particular, are involved in a variety of language-games in the process of sociocultural adaptation. The questions explored in this research were:

1) What are the stages, or types of adaptation that the students experience?

2) How do the students use language-game for their personal, and educational in the process of sociocultural adaptation?

\section{Method}

\subsection{Participants}

The research has been carried out since January 2010 by the authors of this article, meeting participants in person or via Skype. Students of Novosibirsk State University who studied at French universities and higher schools were surveyed about their life and study in France (Note 2). Using the NSU French Center data base (Note 3), 34 informants were selected based their availability and willingness to participate in the study. In this group of informants there are 16 male and 18 female students, with ages ranging from 20 to 25 years. All students are Russians, with Russian as their native language. French proficiency varies from basic to advanced. All informants are currently living in France, with or without scholarship, studying engineering, business, economics, chemistry, or mathematics in higher schools and universities. Considering majors, the totality of the participants has demonstrated a discrepancy with educational trends all over the country; such majors as Economics, Management and French are known to be the most popular among Russian students.

\subsection{Instrument}

Interview was chosen as a qualitative method of interpretation practice in which both of the participants are involved. This method helps understand the meaning of human actions and data in general in a subjective, rather than objective way, and articulates informants as representatives of their own culture (i.e. bearers of the meanings embodied in symbolic forms) in another sociocultural environment, where the respondents transform and fill these meanings with their own experience, feelings, ideas, and attitudes.

Each interview is semi-structured, approximately from one hour to two hours long, which allowed the interviewers to analyze the adaptation of each informant in-depth and single out several language-games that they use to redescribe events of the past. The interview guide contains 14 open-ended questions that require informants to reflect on their personal cultural and educational experiences. For example, there are questions asking about the first weeks of study in France, how life and studies in France are different from life and studies in Russia, some unusual or shocking situations that informants had to face, how one can be successful in studies in France, and what recommendations the informant can give to new-coming Russian students. 
During the conversation, the word "adaptation" was purposefully omitted by the interviewers in all questions in order to observe how respondents choose it for various contexts of their social and cultural life in France. The interviewers were trained in the way they can help the informants point out problematic aspects of life and study in France, stimulating the discussion of situations of language-games, in which their expectations about usual behavioral and communicative patterns were not met, but were established in the dialogue.

Certain "provocations" were used to get the respondents' reflection in order to figure out "unusual circumstances, situations which in some way break the routine" (Giddens, 1984, p. 6). The narration was often accompanied by some kind of emotional experience such as astonishment, surprise, indignation, discomfort, etc. that were the markers of redescription. Despite the fact that these affective components belong to the personal characteristics, they may act as a means of adaptation to the society (Parsons, 1971).

The conversation followed a certain communication format based on symmetric relations of the participants, i.e. the so-called "active" interview where the informants are viewed as competent analysts able to build life events into their own world (Silverman, 2004). According to L. Boltansky, they are "moral observers" (le spectator morale) who possess such traits as impartiality, imaginativeness and emotionality (2007). Therefore, interviewers did not presume or presuppose that they know more than the actors on the field (Bohnsack, 2010), keeping a certain distance from the informants.

\subsection{Data Analysis}

Tape recorded answers of the informants were decoded into text files that allowed to conduct discourse analysis of the texts in order to single out language-games used for sociocultural adaptation.

Data analysis consisted of several steps: 1) determining "problem zones" with some kind of emotional effect on the informant (surprise, embarrassment, excitement, anger, etc.) that stimulated redescription and lead to entering a language-game, 2) finding language-games or elements of a language-game that are repeated in more than one interview, 3) generalization of intersecting language-games in redescriptions of the participants, 4) constructing types of language-games, that are built on the components that are common to all cases, groups, and individuals. The last three types of data belong to the comparative analysis which is recognized as the "golden" standard of methodically controlled research (Nohl, 2010). During the process of comparative discourse analysis, the researchers had to establish and maintain a certain distance from the text in order to objectivize the results.

\section{Results}

The conducted research disagrees with the idea of perceiving the adaptation process as a sequence of stages (Note 4). Language adaptation is usually considered to be the first one to take place (Huang, Chang, 2011), whereas cultural adaptation comes right after. However, in our opinion, these types of adaptation do not appear as stages, but overlap each other, forming a multidimensional structure of the adaptation process. Most of the respondents were confronted with a variety of emerging problems which had to be resolved "here and now."

"I have to act in a different way, not as I used to in Russia... If you have never lived abroad and you have just arrived, at the beginning it is difficult to understand how to behave... It is neither good, nor bad... it is different, and it needs time to get used to it” (Respondent № 9 (Note 5), Ecole Polytechnique, the first year Master's student).

We can talk about at least four dimensions of adaptation where language-game becomes a necessity for Russian students in French universities and higher schools. Communicative practices of the informants reflect the following redescriptions that form the complex picture of their adaptation.

\subsection{Higher Education System: Goals, Methods and Practices}

For the students who got used to a certain educational system in Russia, it is difficult to adjust to the French educational system at higher schools and universities. Significant differences may be found in what is taught in this particular country, culture, and educational system and how it is taught (Samovar, Porter, McDaniel, 2007).

The French educational system is unfamiliar and unusual for them in both methods of instruction, and in the goals that instructors have. The respondents form a picture of an incomplete, imperfect, and mosaic educational environment. Due to the individualized, learner-centered approach in education, students in France have the freedom to choose courses, different topics, and study groups for course projects. In addition, there is a certain independence of students from their professors in research and opinions about the subject matter, which contradicts the teacher-centered characteristic of Russian education. For most Russian students, these features cause the feeling of instability, embarrassment, and astonishment. 
"I felt a little bit embarrassed and lost. In particular, being the first year students at the university, we studied in the same group and contacted with each other, it was like a backbone. Each seminar [in Russia] we felt comfortable enough among your group mates. In France, the students choose the subjects and the students groups change all the time” (Respondent № 20, first year, Ecole Polytechnique, engineering cycle).

One of the reasons why Russian students feel so uncomfortable at the beginning of their study in France lies in educational goals. Novosibirsk State University (NSU) aims to train future scientists, theorists, and researchers, whereas French higher schools focus on training engineers and managers in applied sciences. The recognition of different educational goals makes the respondents redescribe their view on higher education system with its methods and practices.

"NSU is an academic university using the principle "if you don't know the solution, think of your own one". We were trained as researchers. In Ecole we are trained as engineers, i.e. people who are able to apply the ready-made solutions. Less attention is paid to theoretical background of a method and more to how this method can be used"' (Respondent № 26, fourth year, Ecole Polytechnique, engineering cycle).

Another reason is related to the methods of teaching and assessment. For Russian students, courses at higher schools in France are more intensive, comparing to Novosibirsk State University, because of the formative type of assessment. This type includes weekly assignments, quizzes, mid-term examinations and projects throughout the whole course, whereas Russian schools prefer summative assessment, with examinations at the end of the semester that form the grade for each course. Therefore, Russian students in France have to acquire certain time-management and self-organization skills that will help them get their work done before the deadlines almost every week throughout the semester.

"Exams take place during the semester and it often happens that we have five or six exams a week. Still, the classes go on: we can have classes in the morning, exam in the evening, then some sports events; next morning we have another exam, at lunch time we have language classes and in the evening - exam again” (Respondent № 8, the third year student of Ecole des Mines, engineering cycle).

Other educational practices that are unusual for Russian students include the schedule of classes, written task-based examinations, and projects that require application of the material to some real-life situations. Together with deadlines and the amount of work that has to be done, these features of the French educational system may form the feeling of confusion rather than the feeling of confidence about the material being studied.

\subsection{Everyday Life of International Students}

All international students, besides studying, have to solve various everyday problems related to a different sociocultural organization of everyday life. First of all, it includes bureaucracy that students have to confront when obtaining student visas, medical insurance, opening bank accounts, etc. (Debrenn, 2007, 17). For those students who came from Russia, the system of dealing with government agencies seems very unusual.

"If you need to execute a document, you should write a letter, then wait for the response, and then you write a letter again. Every day I come to the dormitory, and I find my mailbox full of letters. All the problems are solved by post, which is a time-consuming process: I write a letter and it needs a week to get to the recipient, and another week to get a response. But it is not necessarily the case that I'm satisfied with the reply" (Respondent № 3, the first year student, School of Advanced Technologies, engineering cycle).

Moreover, the catholic traditions of France influence the opening hours of the organizations in the service industry, which is quite unusual for Russian students. It is interesting how informants redescribe the events of their past that did not match their expectations about social norms and behavioral patterns.

"All the shops close after 20.00 every day and on weekends. At first, I found myself in such a situation when I was very tired at Friday night, and I thought I would go shopping on Saturday or Sunday, but the shops were closed” (Respondent № 9, the first year, Master’s degree student, Ecole Polytechnique).

In addition, during the weekends, French students, unlike international students, usually go home so the dormitories look empty, whereas international students from different countries have to either stay alone in their dormitories, or organize get togethers or trips for their own entertainment. These are the nuances of everyday life that students need to know and adjust to them as fast as possible in order to be successful in the process of adaptation.

\subsection{French Mentality}

Another dimension of sociocultural adaptation is related to the mentality of Russians and the French. Frequently, international students have to join existing student communities with their established relationships, which 
produces a certain level of anxiety. Students were facing the need to adjust to different communication styles and learn the rules of language-game in order to make friends.

"There are people who study there from the first year. They made friends there and try to stick to their groups. There are people who came from other universities and countries who also try to organize themselves in groups" (Respondent № 30, the first year, Master’s student of University Paris-10).

People from the local community maybe reluctant to contact foreigners who speak French with an accent or make mistakes while speaking French.

"If your French is rather poor, they [the French] feel nervous" (Respondent № 18, the second year Master’s student, University of Savoie, Chambéry).

This could be part of the reason why Russian students are more willing to communicate with people of the same culture rather than with French students. This idea is consistent with previous research on international student friendship network patterns (Zhao, Kuh \& Carini, 2005). Even the "open-door" policy of higher schools in France has not led to the extension of contacts of the foreign students with the local residents, younger generations of local residents are reluctant to communicate with foreigners. It is an indicator of diversification process which goes latently on the backstage of the political scene.

"They can be really very friendly and easy-going, but still when one tries to broaden personal contacts with them outside the school, they wouldn't..." (Respondent № 1, doctoral student of the University of Leon-2, has studied at various programs in France).

Being the representatives of an individualistic culture (Schwartz, 2008), French people do not automatically prioritize public life; inversely, their personal motives come first. Russian people do not understand such a "polite and amicable" communication style, when in fact, people do not share the details of their personal and professional life with their friends, preferring to be on their own.

"We should be ready to overcome a moral barrier because we are different with the French. It is difficult to make friends with them... Here I contact with all people, but we do not talk heart-to-heart" (Respondent № 22, the third year student of Ecole Polytechnique, engineering cycle).

Differences in mentality can cause psychological discomfort, disappointment, and depression, leading to the loss of self-confidence in communication and making friends with peers. This is where language-game starts, being used as a tool for understanding differences and overcoming various kinds of barriers that are associated with them.

\subsection{Sociopolitical Life in France}

Despite the individualism in personal relationships of the French, the public life in France, including sociopolitical views and opinions, is the point where solidarity extremely important, which reinforces the complexity of adaptation process for Russian students.

"The French are very social, their mindset is different, they have collective thinking: non-egoistic strong collective feeling" (Respondent № 11, the fourth year student of Ecole Polytechnique, engineering cycle).

The French seem to be more socially and politically active than Russians. The French sense of a "citizen" reflected in the readiness to help their fellows who found themselves in a difficult situation, is very strong. To form the feeling of involvement, international students are expected not only to learn and comply with social norms, but also reach solidarity of their own life with the lives of other people through communication.

One of the indicators of redescription in this case is the recognition of one's social responsibility.

"In fact, we need to consider ourselves as a part of society and learn about the problems it faces"

(Respondent № 12, the fourth year student of Ecole Polytechnique, engineering cycle).

It is interesting that, at the same time, Russian students do not lose their self-identification with Russian culture.

The significance of social integration for contemporary France is shown in the redescriptions that indicate the process of mutual interest from both international students and the French themselves.

"Mutual integration seems necessary; not only are we expected to integrate into the French society. Sometimes it becomes compulsory: even the French have to do something; at the end, it doesn't lead to any convergence" (Respondent № 24, graduate student, Ecole Polytechnique, engineer, 5 years in France). 
The majority of the respondents perceive integration, declared in the public discourse, as "one-way street" where international students are ready to integrate into the French society, but the French themselves are reluctant to allow students do this.

\subsection{Language-Game in the New Sociocultural Environment}

During the interviews, we could observe how each individual lives within the given framework of a "cultural model" and interprets life experiences in relation to the perceived and acquired forms (Eco, 1989). Unless one interacts with solely the representatives of his or her own culture, the "cultural model" is perceived as something self-evident, which does not need to be justified. Being in the French social, cultural, and educational environment, Russian students who participated in the interviews were gradually beginning to perceive other humans as "us" rather than "them" by describing thoroughly "them" and redescribing "us" (Rorty, 1989).

The development of exchange programs and international education in general implies that individuals have to go beyond the limits of their own sociocultural environment and develop their self-awareness, which is highly determined by the ability to enlarge their "final vocabulary" and perceive it as a matter of time and contingency for the success of sociocultural adaptation. For the informants, cultural patterns learned in the process of socialization are not the "evidences of a living world" anymore (Habermas, 1983).

"Here, what I like best is that you can start speaking with a person in the street; nobody will be shocked. If you are in a bus stop, you are 100 percent likely to talk to everybody waiting for the bus. In Russia, we are taught not to talk with the strangers. To be honest, I don't know how I will return back to Russia... how I will go along the streets and not smile. I have no clue about how I will behave there...it is difficult for me." (Respondent № 18, the second year Master’s student, University of Savoie, Chambéry).

The extension of the repertoire of vocabularies and redescriptions allow the students to trace the reasons for their own individual being, telling stories about themselves in a new language (Rorty, 1989). In the situation of entering a new cultural environment, the vocabulary of the respondents was receptive to the most typical social situations, influencing changes in their personality in an intercultural dialogue. Having accepted new norms, values, and behaviors, the respondents start reconsidering their own "cultural model," which may even result in a reverse culture shock.

"I was unwilling to go to France. I liked it here at home. I lived in France for half a year and went home in winter. When I arrived to Moscow, our Russian mindset which I had for 23 years shocked me! I cannot live in Russia anymore. I cannot understand people, as well as the airport staff who say 'Your passport!' Neither 'Hello', nor 'Goodbye'!” (Respondent № 7, the third year student of the Higher School of Restaurant Business).

These examples show how in the situation of an in-depth interview, the informants told their life stories in a new language which goes beyond their previous vocabulary. They drew a line between their actions and the circumstances that influence the behavior of informants, the latter determining the "range and consequences of their choice, going beyond the limits of conscious influence" (Bauman, 2004, p. 9). The language used by the respondents becomes the instrument of not only reflecting, but also constructing the reality; redescription is a means of public justification of the actions conducted in the past that become the basis for the future.

It is not easy to change the habitual vocabulary in order to find easy answers to the complicated questions and challenges of cultural diversity in the contemporary world (Denzin \& Lincoln, 2005). Redescription could be characterized with the ambiguous perception of life, pragmatic reflectiveness, and new behavioral models on "steep turns" in the course of life which can influence the scenarios of further developments. In spite of the fact that these situations break the "normal" (or habitual, or everyday) lifestyle, an individual sees them as essential elements of social life integrity leading to future routinization.

In a multicultural environment, on the one hand, the variety of personal goals is highly appreciated; on the other hand, people have to agree, using a language, with other people about the beliefs, norms, ideals, and values they are going to have. Language-game has become a successful strategy to perceive the world under the conditions of uncertainty and contingency. Involvement in the language-game and accepting its rules in intercultural communication and international education contributes and facilitates the adaptation of international students. In this case, "public moral" is calling for solidarity and the necessity to adjust to each other, whereas "private moral" requires constant self-improvement, openness to the environment, and irony towards ourselves.

\section{Discussion}

Russian students who participated in the research mentioned various adaptation problems that can be divided into four categories, or dimensions. Therefore, we suggest that social adaptation is a product of multiple 
simultaneous processes that occur on different levels such as educational system, sociocultural context, mentality, and sociopolitical life. These dimensions of adaptation were found during this particular research so they might not be the same for other countries and populations.

Based on the interviews conducted with Russian students studying in France, we found out that language-game is a means of entering a different cultural environment, which per se becomes an action of adaptation. Those students who demonstrated, according to Richard Rorty (1989), the ironic mindset rather than "common sense" were more successful in the process of adaptation, and more skillful in learning new vocabularies, switching from one vocabulary to another, and producing their own redescriptions of the events, experiences, people, and themselves.

Rorty's (1989) interpretation of Wittgenstein's language-game, although published more than two decades ago, still gives us cutting-edge answers on questions about modern communication, especially if we view it in an intercultural perspective with its multiple communicative contexts. In addition, Rorty's pragmatism and liberalism bring solidarity to the center of attention. For public rhetoric of contemporary France, solidarity is also perceived as the ideal of social system. Meanwhile, on the backstage of the political scene, there is an opposite process of diversification that creates some kind of a balance between the tendencies of internationalization and preserving the national educational system.

The results of this study reveal some previously unknown aspects of adaptation that international students face, being in different educational, social, and cultural. The conducted research disagrees with the idea of perceiving the process of adaptation as a sequence of stages. We believe that it takes place in the four dimensions simultaneously, that is why it is so difficult for students to become successful in their studies and life in a different country. To take this into account, empirical analysis of sociocultural adaptation must always be multidimensional.

We view language-game as one of the strategies to overcome the problems of adaptation. Students become involved in language-games that exist in different overlapping communicative contexts. The interview responses reflected the multiplicity of purposes that students have entering the communication with the French, their professors, and other international students. For example, most students mentioned their concern about the efficiency of educational process and involvement in social life and activities inside and outside the classroom. In order to fulfill these purposes, students entered language-game that allowed them to learn about the rules for successful interactions.

During the interviews, the informants redescribed the events that were meaningful for them. They presented the interpretations of real facts that influenced their process of adaptation, based on their opinion about the relevance these facts have for them. However, one can think that the interpretations given by the respondents are inherently subjective, and, to a certain extent, not possible to be extrapolated to a larger sample of international students.

The findings are useful for teachers, school administration, international education services at universities and higher schools, they can help understand, advise, and assist international students, including the Russian youth. It is important to realize that adaptation programs for international students are the key to their personal, academic, and social success.

\section{Acknowledgements}

The authors of the article would like to thank the French Center of Novosibirsk State University and its director Michelle Debrenn for providing informants and organizing interviews.

\section{References}

Bauman, Z. (2004). Rasskazannye Zhizni i Prozhitye Istorii [Lives Told and Lives Lived]. Sociologicheskie Issledovania [Sociological studies], 1, 5-14. Retrieved from http://gtmarket.ru/laboratory/basis/4993/4995

Bohnsack, R. (2010). Documentary Method and Group Discussion. Qualitative Analysis and Documentary Method in International Educational Research. Verlag Barbara Budrich, 99-123.

Boltansky, L. (2007). La souffrance à distance. Morale humanitaire, médias et politique; suivi de La présence des absents (2nd ed.). Paris: Gallimard.

Debrenn, M. (2007). Kak Izbezhat' Kul'turnogo Shoka [How to Avoid Cultural Shock]. Cooperation with France in Siberia in the field of higher education: problems and solutions. Brief outline reports. Novosibirsk: $N S U, 16-20$.

Denzin, N. K., \& Lincoln, Y. S. (2005). The SAGE Handbook of Qualitative Research (3rd ed.). Thousand Oaks: Sage. 
Eco, U. (1989). The Open Work. Cambridge, MA: Harvard University Press.

Eco, U. (2004). Otsutstvuyushaya Struktura: Vvedenie v Semiologiu [The Absent Structure: Introduction Into Semiology]. St. Petersburg: Symposium.

Giddens, A. (1984). The Constitution of Society: Outline of the Theory of Structuration. University of California Press.

Habermas, J. (1983). Moralbewußtsein und kommunikatives Handel. Frankfurt am Main: Suhrkamp.

Horne, J. (1989). Rhetoric After Rorty. Western Journal of Speech Communication: WJSC, 53(3), 247-259.

Huang, H., \& Chang, Y. (2011). The Relationship between International Students' and Cross-Cultural Adaptation and Dominant Language in Taiwan. International Journal of Humanities and Social Science, 1(7), 137-145.

Kosenko, S. (2008). Politika Kultury ili Kultura Politiki [The Politics of Culture, or the Culture of Politics]. M.: Vostok - Zapad.

Linklater, A. (2011). Process Sociology and International Relations. Norbert Elias and Figurational Research: Processual Thinking in Sociology, 48-64. http://dx.doi.org/10.1111/j.1467-954X.2011.01978.x

Lyotard, J. F. (1986). The Postmodern Condition: A Report on Knowledge. Manchester: Manchester University Press.

Nohl, A. M. (2010). Narrative Interview and Documentary Interpretation. Qualitative Analysis and Documentary Method in International Educational Research. Verlag Barbara Budrich, 195-218.

Onorati, M. (2010). Building Intercultural Competence in Sociological Perspective. Italian Journal of Sociology of Education, 1, 208-241. Retrieved from www.ijse.eu/index.php/ijse/article/view/57/64

Parsons, T. (1971). The System of Modern Societies. NJ: Prentice-Hall.

Rorty, R. (1989). Contingency, Irony, and Solidarity. Cambridge: Cambridge University Press.

Ryklin, M. (1996). Filosofia Bez Granic [Philosophy Without Grounds]: Conversation with R. Rorty. Logos, 8, $132-154$.

Sablina S. G. (2004). Bar'ery Kommunikacii v Mezhkulturnoy Srede [Communicative Barriers in Intercultural Communication]. Aktual'nye Problemy Mezhkul'turnoy Kommunikacii: Sbornik Nauchnyh Trudov [Contemporary Issues of Communication Theory: Collected works], 52-74. Retrieved from http://www.russcomm.ru/rca_biblio/s/sablina.shtml

Sablina, S., \& Struminskaya, B. (2011). Invisible Dimension of International Communication: Is It Possible to Teach Others "the Right Ethical Standards"? Ethical Issues in International Communication, 201-219.

Samovar, L. A., Porter, R. E., \& McDaniel, E. R. (2007). Communication Between Cultures (6th ed.). Belmont: Thomson Wadsworth.

Schwartz, S. H. (2008). Cultural Value Orientation: Nature and Implications of National Differences. Moscow: Publishing house of SU HSE.

Silverman, D. (2004). Qualitative Research: Theory, Method and Practice (2nd ed.). Padstow: Sage, 2004.

Sisko, L.A., \& Reinhard, K. (2007). Learning to See What's Invisible: The Value of International Faculty Exchange. Business Communication Quarterly, 30, 356-363. http://dx.doi.org/10.1177/10805699070700030409

Sumer, S. (2009). International Students' Psychological and Sociocultural Adaptation in the United States. Counseling and Psychological Services Dissertations, 34. Retrieved from http://digitalarchive.gsu.edu/cps_diss/34

Tran, T. (2008). Mutual adaptation of international students and academics for the sustainable development of international education. Proceedings of the EDU-COM international conference - Sustainability in Higher Education. Khon Kaen, Thailand. Retrieved from http://ro.ecu.edu.au/ceducom/58

Tremblay, K. (2010). Internationalization: Shaping Strategies in the National Context. Bulletin of international organizations: Education, science, new economy, 3, 110-168.

Wittgenstein, L. (1958). Preliminary Studies for the Philosophical Investigations. Generally Known as The Blue and Brown Book. NY: Harper. 
Zhao, C. M., Kuh, G. D., \& Carini, R. M. (2005). A Comparison of International Student and American Student Engagement in Effective Educational Practices. The Journal of Higher Education, 76(2), 209-231.

\section{Notes}

Note 1. Fast Facts and Trends. (2012). Journal of International Student Recruitment, (10),16. Retrieved from www.internationalstudentrecruitment.org/downloads/ELS-Journal-of-International-Student-Recruitment-10-Fall2012.pdf

Note 2. At the present moment, students from other educational institutions such as Altai State University and Novosibirsk State Technical University are being surveyed.

Note 3. For the database, see NSU website http://www.nsu.ru/root.php/omss/fr_center/proposition.xml

Note 4. Gradual development of language competence, i.e. acquiring various "French languages" - academic, spoken, informal, etc. - is the only subject where the sequence becomes apparent. Besides, this development takes place due to the complication of the context: from understanding of one person speaking French, to several people simultaneously talking in a noisy place.

Note 5. To preserve the interviewees' anonymity, they are referred to here by number only. 